\title{
A concessão de benefícios e a aposta na singularidade: um desafio para a Saúde Mental*1
}

Flavia Hasky*2

Ana Paola Frare*3

Este artigo dedica-se à problematização da concessão de benefícios pelo Estado aos usuários dos serviços de Saúde Mental e à reflexão acerca do uso que estes usuários fazem do dinheiro. Fruto da experiência das autoras na estratégia de desinstitucionalização, baseia-se no referencial teórico e clínico da psicanálise para apostar na singularização das práticas que orbitam em torno do manejo do dinheiro no campo da Saúde Mental. Recortes de casos ilustram a problemática.

Palavras-chave: Saúde Mental, concessão de benefícios, psicanálise, singularidade

*1 O trabalho que deu origem ao artigo foi realizado no Instituto Municipal de Assistência à Saúde Juliano Moreira. O artigo teve como base a monografia " "Se tiver que ganhar mais eu não vou': considerações sobre o uso do dinheiro pelos usuários de Saúde Mental", apresentada por Flávia Hasky ao IPUB/UFRJ como requisito final para a obtenção do título em Saúde Mental nos moldes de Residência, apresentada no IMAS Juliano Moreira em 2010.

*2 Escola Brasileira de Psicanálise - EBP (Rio de Janeiro, RJ, Br).

${ }^{* 3}$ Universidade Federal Fluminense - UFF (Niterói, RJ, Br). 
A concessão e administração de benefícios para usuários da rede de Saúde Mental é um dos "nós" que sustentam e amarram o trabalho nesse campo. Tendo a Reforma Psiquiátrica Brasileira (RPB) uma aposta na estratégia de "desinstitucionalização", ${ }_{1}$ a garantia de direitos mínimos e a necessidade de possibilitar o acesso a bens de consumo se fazem mister. $\mathrm{Na}$ esteira dessas construções e apostas, a reabilitação social, autonomia e contratualidade social ganham cena e protagonizam um novo arranjo de serviços e concepções de tratamento que buscam garantir ao usuário internado em longa permanência a possibilidade de viver na cidade, sustentando sua presença a partir dessas novas práticas. Nessa direção torna-se tarefa dos serviços garantir os benefícios aos quais os usuários têm direito, possibilitando assim a execução de um projeto sustentável de saída do ambiente hospitalar.

Um exemplo é o programa "De volta pra casa". Os critérios utilizados demonstram que, para além de uma necessidade concreta do dinheiro para viver na cidade, há ainda um reconhecimento do Estado de que sua omissão na formulação e execução das políticas públicas para saúde mental contribuía - e de certo modo incentivava - a permanência hospitalar.

Nesse artigo, analisaremos a prática de concessão de benefícios pelo governo federal aos usuários de Saúde Mental, tendo como foco problematizar a "naturalização" desta. Partindo da experiência das autoras na estratégia de desinstitucionalização, do encontro com pacientes para os quais o benefício se apresentou como uma questão, realçaremos a importância de se trabalhar segundo a singularidade de cada caso, levando em consideração a subjetividade.

A ideia da RPB é promover um processo de emancipação e não somente a aplicação da concessão de direitos. Assim, ao mesmo tempo

\footnotetext{
${ }^{1}$ Por este termo, entendemos não só os movimentos de desospitalização que marcam a agenda da RPB, mas também uma desconstrução de saberes e práticas há muito institucionalizados no tratamento da loucura.
} 


\section{SAÚDE MENTAL}

que se deve garantir a possibilidade concreta de viver na cidade, assegurando esse direito, não se pode perder de vista a quem ele se destina. O desafio é, portanto, compor uma tessitura em que as políticas do SUS e o pensamento clínico componham uma argumentação harmônica. Sendo o sujeito e seu pathos psíquico o centro dessa discussão, toda ação deve levar em conta suas paixões, seu sofrimento, sua voz única.

\section{O dinheiro no campo da Saúde Mental}

No contexto das políticas de Assistência Social do Brasil, os usuários de Saúde Mental começaram a ser contemplados por volta dos anos 1990 na categoria de portadores de deficiência. De acordo com a política de proteção social em vigor, os loucos pertencem à parcela da população excluída economicamente. Como esclarece Assumpção (2004), "a intenção do legislador é de assegurar àqueles que são considerados à margem, condições mínimas de participação influente na vida ativa da sociedade. Para tanto, foram criadas ao longo das últimas décadas linhas básicas para um processo de integração desses cidadãos à sociedade" (p. 47).

Além da supracitada bolsa "De volta pra casa", há bolsas oferecidas pelos governos municipais, assim como as aposentadorias por invalidez, o auxílio-doença ligado ao INSS, a Bolsa-Família, entre outras fontes de renda desse tipo, às quais todos os cidadãos brasileiros que necessitam têm direito, sejam eles loucos ou não. Destacamos o Benefício de Prestação Continuada - BPC -, também chamado de "Benefício de amparo assistencial ao idoso e ao deficiente", que requer a comprovação da ausência de meios de prover a própria manutenção, além de não tê-la provida por sua família como condição ao direito de recebê-lo. Outra exigência legal é a incapacidade para a vida independente e para o trabalho. Sublinhamos aí a curiosa contradição intrínseca à lei, contradição essa que impulsiona a problematização à qual nos propomos neste artigo: se, por um lado, os benefícios promovem a possibilidade da reabilitação através de uma renda mínima, acabam produzindo a manutenção de uma condição incapacitante dos que sofrem de transtornos mentais, taxados como "deficientes". Contradição tributária de uma forma de tratamento que ordenou o campo da atenção, explicitada, junto a outras tantas, quando se reordena o modelo e a concepção da assistência.

Assumpção (2004) aponta para a complexidade que é esse modo de concessão de benefícios, questionando o fato de o "critério de elegibilidade para o recebimento afirmar que o usuário só o receberá se for atestado como incapaz para o trabalho, o que parece apontar para o sentido oposto de sua proposta 
inclusiva" (p. iv). É uma questão espinhosa e que não possui fácil solução, já que muitos dos pacientes de longa permanência não têm mais condições laborativas, tampouco de gerenciamento de seu próprio benefício. Por outro lado, não podemos nos ater às políticas que a Saúde Mental tem acesso sem pensar no coletivo social ao qual são destinados esses benefícios. O que propomos recortar então é o manejo que se faz necessário para operar a partir da concessão, tomando o singular de cada caso como baliza para pensar a assunção dos pacientes aos benefícios.

Em nossa prática, Cláudio e seu técnico de referência muito nos ensinaram a esse respeito. Cláudio é um paciente psicótico que recebia uma bolsa e, além dessa fonte "oficial" de renda, contava em seu delírio com outro valor, bem maior do que esse. Afirmava ser primo de uma celebridade, com quem frequentemente falava ao telefone e que lhe enviava altas quantias em dinheiro. Era comum Cláudio ficar apertado no fim do mês e então dizia que dessa vez o primo não pudera ajudá-lo, mas que o faria em breve. É interessante o modo que seu técnico de referência construiu para que o paciente conseguisse, minimamente, controlar seu próprio dinheiro. Incluindo o delírio do paciente na intervenção clínica, propôs o seguinte combinado: “no dinheiro do 'primo' eu não vou mexer, você dará seu jeito. Em relação ao dinheiro da sua bolsa é diferente, a gente tem que pensar juntos como fazer". A partir disso, o paciente conseguiu passar a pedir ajuda para se organizar em relação ao que ganha e ao que gasta.

Tendo a aposta na transferência como estratégia clínica adotada, reforçou-se o vínculo entre eles e consequentemente a possibilidade de sustentação de projetos futuros (como a saída da instituição para uma moradia assistida). Caso contrário, o paciente provavelmente pensaria: "como é que vou confiar nele sem que acredite nisso que é o mais verdadeiro para mim, que eu sou primo do fulano. Como ele pode ser meu técnico de referência se não considera esta que é, para mim, a maior referência?!". Tal como nos fala Berlinck (1998) acerca da posição clínica, vemos nesse exemplo o inclinar-se "diante de alguém que porta uma voz única a respeito de seu pathos, de sua tragicomédia” (p. 56). Nessa "experiência que pertence aos dois" (p. 55), que é "sempre objeto da transferência, ou seja, de um discurso que narra o sofrimento, as paixões, a passividade que vem de longe e de fora e que possui um corpo onde brota, para um interlocutor que, por suposição, seja capaz de transformar, com o sujeito, essa narrativa numa experiência" (p. 57).

Ações prescritivas, que automatizam o usuário como louco ou incapaz, devem dar lugar, portanto, a uma prática de cuidados refinados e afinados à clínica, na qual a relação do usuário com o benefício que recebe é trabalhada em seu tratamento. 


\section{SAÚDE MENTAL}

\section{Contribuições da psicanálise a esse debate}

A partir da psicanálise, Serpeloni (2007) analisa essa questão fazendo uso da noção de sujeito. A pesquisadora visa investigar de que forma os benefícios concedidos pelo governo aos "deficientes mentais" podem corroborar para a manutenção de um sintoma. Procura mostrar, a partir do que observa em sua prática clínica, que uma criança autista ou psicótica sofre consequências por ter recebido um benefício para auxiliá-la em seu tratamento. Aponta como problemática a "aposentadoria" recebida, o que nos faz pensar no lugar que essa criança ocupará no seio familiar e no destino que lhe está sendo tão precocemente traçado.

Saraceno (1999) enfoca o quanto o trabalho é algo importante para um processo de reconstrução que vise a um exercício pleno de cidadania, por sua potencialidade de aumentar as oportunidades de troca de recursos e de afetos. Nesse sentido, investir em projetos de trabalhos assistidos, assim como em oficinas de geração de renda, vem se mostrando uma excelente estratégia, em franco crescimento, apesar das limitações de ordens diversas.

Há, portanto, tantos arranjos sintomáticos quanto beneficiários. Há os que não lidam muito bem com a perda de uma "identidade funcional" que os referencia, saudosos de um tempo e de um lugar; há os que fazem do ganho do benefício uma razão a mais para não reconfigurar suas formas de gozo; há os que não suportam receber um benefício porque não possuem retaguarda simbólica para operacionalizar o que há de simbólico nessa 'moeda de troca'. E há, claro, as ações bem-sucedidas, onde o provento fará a estrutura para possibilitar a vida na cidade. Há modos distintos, teorias próprias, saberes instituídos, mas não um consenso sobre seu manejo e consequências. Aos praticantes da psicanálise cabe não recuar em equivocar demandas, repensar direções e considerar que o "bem querer" não está sempre afinado ao "bem dizer". Daí a importância de se dar uma atenção à origem do pedido: é o próprio paciente que o reivindica? $\mathrm{Ou}$ um de seus familiares ou até mesmo pessoas conhecidas? É legítimo que o desejo de conseguir um benefício parta de um profissional sem que este implique o paciente de quem cuida no processo? E quando o paciente não tem possibilidade de gerenciamento, quem deve fazê-lo? E se quiser recusá-lo? Perguntas iniciais que equivocam a concessão 'no atacado' e apontam para um negócio que só pode dizer de um cuidado se for feito no varejo, no caso a caso.

Perguntas suscitadas a partir da escuta de sujeitos como Denis, paciente com quadro de esquizofrenia grave, que passou anos internado até ir para um serviço de moradia, onde o conhecemos. A razão que justificou sua longa permanência no hospital, mesmo em tempos em que a Reforma Psiquiátrica já estava a todo vapor, é eminentemente clínica, baseada na singularidade do paciente. Segundo o 
delírio de Denis, sua família havia sido enterrada ali e ele não aceitava ficar longe deles.

Depois de muito trabalho junto à psicóloga que o acompanhava, sua desospitalização tornou-se possível. O recurso que o próprio paciente criou para suportar essa mudança foi extremamente curioso: passou a negar que era o Denis e assim não teria abandonado sua família. Foi a saída que inventou para conseguir sair daquele lugar e ir para outro. Ao deixar de ser Denis passou a nomear-se Jesus Cristo, apresentando-se e inclusive assinando como tal.

Se essa saída foi exitosa, por um lado, trouxe algumas questões, justamente em relação à questão do dinheiro. Assinando como Jesus, ele perdeu o benefício que vinha ganhando havia anos. E não havia forma de convencê-lo, com o argumento que fosse, de que precisava voltar a assinar 'Denis'. Dizer que não tinha sentido, que assim ele estava se prejudicando, que precisava do dinheiro, não adiantava. E a equipe precisou suportar por um tempo que Denis ficasse sem esse dinheiro ao qual por lei tinha direito, já que não era esta a lei que regia seu funcionamento psíquico naquele período.

Nesse sentido, Leal (1999) nos alerta em relação aos perigos da paixão do cuidar. A autora associa a paixão excessiva do cuidar a uma redução nas possibilidades de se enxergar algo além. A clínica que propõe tem como um de seus "princípios-guia" um cuidado marcado pela provisoriedade. São os aspectos de cada situação que indicam o caminho a ser seguido. Na Saúde Mental a clínica é de riscos e incertezas, com saberes parciais e sujeitos em ressignificação, o que exige dos profissionais um exercício permanente de escuta da diferença, das singularidades. As tomadas de decisões, por vezes embaraçosas, por vezes inusitadas, devem se orientar não pela via da caridade, mas pela radicalidade de um saber-não-saber, que delineia a posição do analista como alguém que tributa o saber ao sintoma.

\section{Considerações psicanalíticas sobre o dinheiro}

Meio circulante oficial, o dinheiro é usado como o equivalente geral das mercadorias. A psicanálise o vê como algo complexo, por estar relacionado com diversos outros elementos de nosso psiquismo, em especial a sexualidade. Em linhas gerais, podemos dizer com Freud e Lacan que cada um lida com o dinheiro de uma forma muito própria, singular e que não há ninguém que saiba lidar completamente bem com isso. A ideia é que o manejo do dinheiro, de uma forma ou de outra, traz questões para todos nós. Curiosamente, nos relata Garcia (2003), o próprio Lacan escreve a seguinte frase a Pierre Martin: em questões de dinheiro não se permite nada, "eu sou intratável". Freud, por sua vez, gostava do adágio “somente a morte é grátis" (p. 97). 


\section{SAÚDE MENTAL}

No cotidiano de nosso trabalho, escutamos de Gerson fala semelhante, revelando, à sua maneira, embaraços com relação ao dinheiro. Certo dia, sentia-se mal e ao conversarmos lhe perguntamos sobre a medicação, propondo-lhe uma consulta de revisão com o psiquiatra. O discurso que Gerson proferiu como resposta diz muito sobre si, sobre seu pathos psíquico enquanto sofrimento na lida com o dinheiro: "Os remédios não estão sendo um problema, vemos isso depois, diminui um, põe outro. As vozes me incomodam, mas eu dou um jeito, elas vão embora (sua técnica própria para pará-las é gritar bem forte: "Sai!"). O meu maior problema, o que me tira o sono, me dá a maior dor de cabeça, é o dinheiro: Quando eu tenho é um problema e quando eu não tenho também!".

O artigo "Dinheiro é psicológico" aponta para a correlação não tão direta entre situação financeira e saúde emocional, pois "cada pessoa tem um jeito peculiar de lidar com dinheiro e, ao contrário do que a maioria das pessoas espera, ter dinheiro não significa ter mais paz de espírito" (Campos, 2003, p. 11). Como alerta Quinet (2002), as questões de dinheiro e as de sexo dividem o sujeito. As respostas às questões de dinheiro, assim como às de sexo, são sempre singulares: "não há duas pessoas que tenham a mesma relação com o dinheiro" (p. 87).

Freud (1913/1996c) afirma que "poderosos fatores sexuais acham-se envolvidos no valor que é atribuído ao dinheiro" (p. 146), acrescentando que as questões de dinheiro são tratadas da mesma maneira que as questões sexuais com a mesma incoerência, pudor e hipocrisia. Tal aproximação entre o dinheiro e a sexualidade leva à constatação de que o dinheiro é libidinal, de que está ligado à obtenção de uma satisfação.

Outras associações trazidas por Freud (1908/1996a) à questão do dinheiro são o poder e o controle. O dinheiro como símbolo do poder é explicado pela marca fálica que lhe é atribuída, que mascara a falta-a-ter, conferindo a ilusão de que com ele tudo se pode. A relação com o controle aparece na equivalência com as fezes, sendo ambos "intimamente relacionados com a sujeira" (p. 162). Há ainda o paralelo entre o movimento de reter/soltar as fezes com o movimento de guardar/gastar o dinheiro. ${ }^{2}$

O dinheiro é pensado também em aproximação com o sintoma, sendo seu uso sintomático. Essa talvez seja a indicação mais preciosa quando pensamos no manejo da concessão de benefícios na estratégia de desinstitucionalização. $\mathrm{Na}$ clínica, Freud percebe que o sintoma é caro para o sujeito e passa a se interessar em saber como a doença e, particularmente o sintoma, poderiam ser amoedados pelo dinheiro. O sujeito tem satisfação com seu sintoma e, ao constatar isso, Freud irá falar em dois tipos de benefício, isto é, lucros na economia libidinal. O

${ }^{2}$ Mais sobre o tema em Laia (2004).

Rev. Latinoam. Psicopat. Fund., São Paulo, 19 (1), 99-113, mar. 2016 
primeiro é o beneficio primário, que é ficar doente: dessa 'fuga para a doença' se tira alguma vantagem. Já o benefício ou ganho secundário deriva do primeiro e, através dele, tiram-se ainda mais vantagens da doença. O que Freud demonstra é que aquilo que parece ser evidente — retomar a saúde — não o é. Há alguma coisa entre a queixa, o sofrimento e o desejo de deixar essa condição que não é óbvia. Tal proposição nos serve para pensar nos casos de usuários que se cristalizam na posição de 'doentes mentais' para não deixarem de ganhar o benefício do governo. São situações em que o modo como se lida com o dinheiro (ou com sua condição para obtê-lo) está alegoricamente marcado pelo sintoma, pela forma de organização subjetiva que cada um monta para si a partir da submissão à linguagem e ao campo do Outro.

O dinheiro só existe em função da linguagem, já que o homem nasce envolvido por seu manto e, portanto, sujeito à ordem simbólica. Sobre isso, Souza (1997) revela que o significante dinheiro aparece no discurso dos analisandos em sua radical singularidade, trazendo consigo seus equívocos. Laia (2004) nos diz da incidência do dinheiro como um $\mathrm{S}_{1}$, "significante fundamental em jogo nas trocas que corporificam a vida de um sujeito" (p. 24). Na própria obra freudiana, o caso do "Homem dos Ratos" (Freud, 1909) ilustra bem esse ponto, dada a equivalência entre tantos florins (nome da moeda do país em que o paciente vivia) e tantos ratos, provocada pela homofonia em alemão entre os dois termos. $\mathrm{O}$ paciente instituiu uma "moeda corrente de ratos" e através desse fenômeno de linguagem Freud pôde tirar novas conclusões acerca de sua dificuldade em pagar uma antiga dívida. O significante "rato" entrou na série de equivalências fálicas - dinheiro, pênis, filho.

Essa submissão às leis da linguagem leva à impossibilidade de desfrutarmos integralmente, fato que distingue o sujeito da psicanálise do sujeito do Direito. Segundo Barros (2007), a ordem do sistema jurídico — com a satisfação das demandas sociais - depende da interlocução não apenas de seus elementos internos, mas, também, do que extrapola os limites do estritamente jurídico. Por essa razão, a decisão de se conceder um benefício a um paciente deve passar necessariamente por aquilo que este diz e pelos caminhos que sua fala indica. É, portanto, uma decisão a ser tomada "na e da situação clínica, a partir daquilo que é dito pelo paciente e escutado pelo clínico", este "movimentando-se como se fora uma embarcação ancorada pela fala do paciente” (Berlinck, 2004, p. 8).

\section{Telma, João e o manejo singular com o dinheiro}

Ao atendermos pacientes que passaram a ser contemplados com algum benefício do governo fomos, tendo a clareza do quanto a lida com o dinheiro 


\section{SAÚDE MENTAL}

diz muito mais sobre a subjetividade do que propriamente sobre a economia, as finanças. Seja no âmbito das neuroses ou das psicoses, o clínico que atua na Saúde Mental não pode se furtar em assumir que a relação com o dinheiro revela efeitos importantes de sujeito.

Telma é uma paciente que afirmou que ter dinheiro não é uma meta universal. O dinheiro para ela é algo especialmente difícil de lidar e tal fato parece ter a ver com sua história de vida. Nasceu em uma família muito pobre, em sua casa as coisas faltavam e ela sempre fala disso. Desde pequena se acostumou a viver com pouco e, após surtar e ser internada por longos anos, manteve esse padrão, tendo que dividir com os colegas o pouco que tinham.

Já em processo de desospitalização, recebia uma bolsa modesta e recusava-se veementemente a ir ao INSS solicitar outro benefício, ao qual tinha direito. Para ela, o argumento de que poderá receber mais dinheiro não tem sentido. "Eu tô bem com esse dinheiro" e "eu vivo bem sem dinheiro", repetia irritada, caso insistissem. Gastar tudo e ficar sem não é problema para ela. Ao contrário, forjava neste "estar sem" uma posição subjetiva: a de pedinte. Assim tentava fazer laço, sendo essa uma forma possível de interagir. Vive pedindo cigarros porque deu todos que tinha. E quando compra um maço, se pediu emprestado um, paga com cinco.

Além de "dar tudo que tem" costuma presentear sua técnica de referência quando saem pelo bairro. Nessas ocasiões, em que o manejo clínico se dá no contexto do acompanhamento terapêutico, Telma praticamente exige que sua técnica lanche o mesmo que ela, ficando muito aborrecida quando esta se coloca como desejante, só aceitando o que quer. Como Telma compra as coisas sem se pautar pela lógica do "eu preciso disso?", "eu quero isso?", "vale a pena gastar com isso, ou com outra coisa?" - perguntas do campo das neuroses —, é difícil para ela acolher tal atitude. Não compreende uma lógica que não seja imperativa de gastar, esse gozo que advém do Outro, impositivo. Ao posicionar-se como sujeito de desejo, a técnica indica que o Outro pode ser barrado e tenta ajudar Telma a enfrentar situações que se repetirão no convívio social, na experiência de ser louca e também uma cidadã que consome.

Certa vez, na Páscoa, recebeu em uma "bolada" só várias bolsas atrasadas. Diante da notícia mostrou-se angustiada, entrando em estado maníaco. Precisava sair às compras para gastar todo o dinheiro em ovos de Páscoa. "Quero encher esse lugar de ovos de Páscoa"; "Vamos comprar logo porque tem muita gente no mundo, não vai sobrar ovo pra mim", insistia aflita. "Quero acabar com esse dinheiro, nem que tenha que dar porrada nele!" E acrescentava em voz mais alta: "Pá, pá, pá, vou acabar com esse dinheiro!". Telma precisava urgentemente acabar com o dinheiro para que ela, como sujeito, não acabasse.

O "ponto de basta", presente na metáfora paterna, não opera para Telma, o que faz com que as compras desenfreadas sejam a única possibilidade de 
resposta ao Outro. Soler (2002), falando do famoso caso Schreber, nos indica o que acontece nessa relação do sujeito, do Outro e do objeto quando não estão ordenados pela função fálica: uma desarticulação do Real, Simbólico e Imaginário, deixando ao sujeito a possibilidade de estruturação de uma metáfora, ou ao menos um delírio, que tente enodar aquilo que está sem ordenação. Um verdadeiro "vendaval" para Telma, que, sem retaguarda simbólica, precisa acabar com seu dinheiro para sobreviver e seguir "pedinte".

Comprar coisas que remetam a estabilidade e permanência não the faz bem. Foi o caso do armário que comprou para ir tornando mais concreto um projeto de moradia. Nesse dia falou: "É a primeira compra grande que vou fazer na minha vida". Quando o móvel chegou, indagou perplexa: "E agora...?”.

Vemos que compra grande para ela é o armário e não muito dinheiro em chocolate. Não é o quanto se gasta de uma vez o que importa e sim no que se gasta, o que isso representa para ela. Diferente de uma quantia em dinheiro bruto, o armário (material) aponta em direção à casa, questão delicada para quem é fortemente marcada pela institucionalização. E tem mais um ponto em que reside sua dificuldade de sair da instituição, expressado claramente nesta frase inusitada: "Se tiver que ganhar mais eu não vou!" (falou isso assim que soube que ir para uma casa significa ter direito a mais uma bolsa). Se já é difícil administrar, tanto prática quanto psiquicamente, o dinheiro que tem, imagina se tiver mais ainda.

No tratamento de João, escutar sua reação à oferta da concessão de um benefício foi para nós uma verdadeira experiência, a partir da qual fomos levadas a pensar coisas novas. Nos trouxe a "possibilidade de se pensar aquilo que ainda não foi pensado" (Berlinck, 1998, p. 57) tanto sobre o próprio paciente quanto sobre as articulações teórico-clínicas. Paranoico, que sofre por sempre estar na posição de objeto de gozo do Outro, João também surpreendeu a todos diante da proposta súbita de ganhar um benefício. Expressando uma desconfiança condizente com seu quadro clínico, perguntou: "De onde vem esse provento?!". Aquilo que lhe seria "dado" não é lhe pareceu um bem, afinal, ele não tinha feito nada para merecê-lo. A desconfiança paranoica não cessa diante das explicações sobre direitos, e "se colocarmos o sujeito e o Outro cara a cara, a divisão fica claríssima: no delírio, o Outro acusa o sujeito supostamente inocente" (Soler, 2002, p. 58). O que lhe é oferecido como benefício não entra pacificamente para sua ordenação de sujeito, que toma aquilo que lhe é direito como algo que o persegue, o acusa. "De onde" as coisas supostamente dadas chegam, torna-se mais importante do que o provento em si.

Algo parecido ocorreu com Ribas (Macedo et al., 2003), paciente psicótico que entrou em crise na chegada à residência terapêutica em que passaria a morar após anos de internação. Os técnicos identificaram que foi justamente este o fator desencadeante de sua desestabilização, ao escutarem o paciente expressar, 


\section{SAÚDE MENTAL}

assustado: "O que fiz para merecer isso?" (p. 92). Dessa experiência, a equipe constatou que "(...) o paciente se imbuiu de insígnias paternas para as quais não tinha retaguarda simbólica (p. 93)". A partir desse episódio fortaleceram a defesa (com a qual fazemos coro) de que os direitos dos cidadãos devem ser respeitados, "inclusive o de não querer se beneficiar pelas ofertas de um programa" (p. 94). Por fim os autores falam de adaptar os regulamentos aos casos, "em favor das formas vivas do desejo" (p. 96).

\section{Considerações finais}

Ribas, João, Telma, Gerson, Denis, Cláudio e tantos outros usuários da Saúde Mental nos ensinaram que a lida com o dinheiro sempre traz consigo algum sofrimento e diz muito sobre o pathos psíquico de cada um. Nessa experiência vivida, compartilhada, tornou-se clara a necessidade de trabalharmos tomando clínica e política como indissociáveis. É a clínica, a dinâmica psíquica de cada caso que sustenta uma política, sendo a subjetividade o que sustenta a clínica.

Orientados não apenas por leis, mas por um desejo que aponta para emergência do sujeito, não podemos recuar diante dos impasses da responsabilização e tessituras da construção subjetiva de cada um em nome de um "bem querer" (Laia, 2004). As regras gerais só interessam se subjetivadas. É preciso fazer valer os recursos subjetivos como meios de manejar a convivência, implementando assim uma lógica coletiva que leve em conta o traço de cada um. Como vimos, a ideia de que todo benefício traz benefício se mostrou equivocada em nossa experiência clínica, apontando para o fato de que o benefício é importante, mas não suficiente para que mudanças e melhorias ocorram na vida dos usuários, já que a transformação da realidade objetiva é essencial, mas não suficiente para tal. Nas palavras de Lossada (2001), caminhamos na direção de que se "realize a norma e se efetue a lei vivificando-a pelo uso singular que alguém faz dela" (p. 162). O saber, portanto, está do lado do sujeito, não sendo algo prévio, interior às leis que regem uma política geral. ${ }^{3}$

${ }^{3}$ Agradecemos a Paula Borsoi pela orientação da monografia " "Se tiver que ganhar mais eu não vou': considerações sobre o uso do dinheiro pelos usuários de Saúde Mental”, apresentada ao Instituto de Psiquiatria da Universidade Federal do Rio Janeiro - IPUB/UFRJ como requisito final para a obtenção do título em Saúde Mental nos moldes de Residência. 


\section{Referências}

Assumpção, S. S. F (2004). Benefício de prestação continuada: uma estratégia para autonomia? Dissertação de mestrado, Programa de Mestrado em Saúde Pública Políticas Públicas e Saúde, Fundação Oswaldo Cruz, ENSP, Rio de Janeiro, RJ.

Barros, F. O. (2007, julho-dezembro). O objeto $a$ é um fundamento do laço social. Almanaque on-line, Revista Eletrônica do IPSM-MG, 1(1). Recuperado de: <http://www. institutopsicanalise-mg.com.br/psicanalise/almanaque/.htm $>$.

Berlinck, M. T. (1998, março). O que é a psicopatologia fundamental. Revista Latinoamericana de Psicopatologia. Fundamental, São Paulo, 1(1), 46-59.

Berlinck, M. T. (2004, setembro). O "fundamental” da psicopatologia fundamental. Revista Latinoamericana de Psicopatologia Fundamental, São Paulo, 2(3), 7-11.

Campos, R. (2003, maio). Dinheiro é psicológico. Revista Viver Psicologia, São Paulo, ano $X I(124), 10-14$.

Freud, S. (1996a). Caráter e erotismo anal. In Edição Standard Brasileira das Obras Psicológicas Completas de Sigmund Freud (pp. 157-164). Rio de Janeiro: Imago. (Trabalho original publicado em 1908).

Freud, S. (1996b). Notas sobre um caso de neurose obsessiva. In Edição Standard Brasileira das Obras Psicológicas Completas de Sigmund Freud (pp. 137-273). Rio de Janeiro: Imago. (Trabalho original publicado em 1909).

Freud, S. (1996c). Artigos sobre Técnica - Sobre o início do tratamento. In Edição Standard Brasileira das Obras Psicológicas Completas de Sigmund Freud (pp. 137-158). Rio de Janeiro: Imago. (Trabalho original publicado em 1913).

Garcia, G. (2003, agosto). La estructura libidinal del dinero. Revista da EOL, Buenos Aires, 1(1), 95-97.

Laia, S. (2004, abril). Dinheiro e psicanálise. Correio, Belo Horizonte, 47, 22-24.

Leal, E. M. (1999). Tudo está em seu lugar? Da importância de irmos além dos princípios gerais na discussão da prática dos serviços-dia. Cadernos IPUB / Instituto de Psiquiatria da UFRJ, Rio de Janeiro, 14, 47-54.

Lossada, C. (2001) Mercados: en busca de la singularidad perdida. Revista da Escuela de la Orientación Lacaniana - EOL/Rosario - Fundación, 161-164.

Macedo, L. F. et al. (2003, setembro). Uma casa para Ribas. Opção Lacaniana, Rio de Janeiro, 37, 92-96.

Quinet, A. (2002). As $4+1$ condições da análise (9. ed.). Rio de Janeiro: Jorge Zahar.

Saraceno, B. (1999). Libertando Identidades: da Reabilitação psicossocial à cidadania possível. Belo Horizonte/ Rio de Janeiro: Té Corá Editora/Instituto Franco Basaglia.

Serpeloni, F. (2007). Análise das possíveis consequências do recebimento de benefícios mensais por crianças consideradas deficientes mentais. Projeto de Pesquisa para Dissertação de Mestrado, Programa de Mestrado em Saúde Pública, Políticas Públicas e Saúde, Fundação Oswaldo Cruz/ ENSP, Rio de Janeiro, RJ. 


\section{SAÚDE MENTAL}

Soler, C. (2002). O inconsciente a céu aberto. Rio de Janeiro: Jorge Zahar.

Souza, N. S. (1997). A questão do dinheiro na psicanálise. Agenda: Revista de Psicanálise, Rio de Janeiro, 242-245.

\section{Resumos}

(Conceding benefits and betting on singularity: a challenge for Mental Health)

This paper focuses on problematizing the State's concession of benefits to Mental Health service users, and on reflecting about the use the latter make of this money. Result of the authors' experience in deinstitutionalization strategies, this paper is based on the theoretical and clinical references of psychoanalysis - betting on the singularization of practices that exist in and around dealing with money in the field of Mental Health. Examples of clinic cases illustrate the problems.

Key words: Mental Health, concession of benefits, psychoanalysis, singularity

(L'octroi d'avantages et le pari sur la singularité : un défi pour la santé mentale)

Cet article est consacré à la problématisation de l'octroi d'avantages par l'État aux utilisateurs des services de santé mentale et à la réflexion sur l'usage que ces utilisateurs font de l'argent. Fruit de l'expérience des auteures dans la stratégie de la désinstitutionalisation, il se base sur le référentiel théorique et clinique de la psychanalyse pour parier sur la singularisation des pratiques qui gravitent autour du maniement de l'argent dans le domaine de la santé mentale. Des extraits de cas illustrent la problématique.

Mots clés: Santé mentale, octroi d'avantages, psychanalyse, singularité

(La concesión de beneficios y la apuesta en la singularidad: un desafío para la Salud Mental)

Este artículo se dedica a la problematización de la concesión de beneficios por parte del Estado a los usuarios de los servicios de salud mental y a la reflexión acerca del uso del dinero por parte de estos usuarios. Fruto de la experiencia de las autoras en la estrategia de desinstitucionalización, este artículo se basa en la referencia teórica y clínica del psicoanálisis para apostar en la singularización de las prácticas que orbitan alrededor del manejo del dinero en el campo de la Salud Mental. Recortes de casos ilustran la problemática.

Palabras clave: Salud Mental, concesión de beneficios, psicoanálisis, singularidad 
(Leistungsgewährung und Singularität: eine Herausforderung für die psychatrisische Versorgung)

Dieser Artikel diskutiert die Gewährung von staatlichen Leistungen an Patienten, die an psychischen Problemen leiden, sowie die Verwendung dieser Leistungen. Diese Arbeit beruht auf den theoretischen und klinischen Grundlagen der Psychoanalyse, sowie auf den Erfahrungen der Autorinnen mit De-institutionalisierungsstrategien. Der Artikel schlägt die Singularisierung der Maßnahmen vor, die diese Leistungen betreffen, was anhand von bestimmten Fällen illustriert wird.

Stichwörter: Psychische Versorgung, Leistungsgewährung, Psychoanalyse, Singularität

(健康福利支付和精神病的特殊性：对精神健康体系的挑战）

本论文讨论健康福利在精神健康体系的开支使用, 特别是健康福利经费的 使用方面的问题。论文作者多年研究精神病治疗体系, 参照心理分析学理论和 临床实践, 提出去机构化的战略, 把焦点聚集在精神病的特殊性上, 精神病的 特殊性质决定了精神病治疗的费用使用方面的特殊性。作者举例一些病例来展 示健康福利系统在精神病治疗方面的费用的使用上的问题。

关键：精神健康, 健康福利支付, 心理分析学, 独特性。

Citação/Citation: Hasky, F.; Frare, A.P. (2016, março). A concessão de benefícios e a aposta na singularidade: um desafio para a Saúde Mental. Revista Latinoamericana de Psicopatologia Fundamental, 19(1), 99-113.

Editores do artigo/Editors: Profa. Dra. Ana Cristina Costa de Figueiredo e Profa. Dra. Andrea Máris Campos Guerra

Recebido/Received: 27.10.2015/ 10.27.2014 Aceito/Accepted: 29.1.2015 / 1.29.2015

Copyright: (C) 2009 Associação Universitária de Pesquisa em Psicopatologia Fundamental/ University Association for Research in Fundamental Psychopathology. Este é um artigo de livre acesso, que permite uso irrestrito, distribuição e reprodução em qualquer meio, desde que o autor e a fonte sejam citados / This is an open-access article, which permits unrestricted use, distribution, and reproduction in any medium, provided the original authors and sources are credited. 


\section{SAÚDE MENTAL}

Financiamento/Funding: As autoras declaram não ter sido financiadas ou apoiadas / The authors have no support or funding to report.

Conflito de interesses/Conflict of interest: As autoras declaram que não há conflito de interesses / The authors have no conflict of interest to declare.

\section{Flávia Hasky}

Psicóloga e Psicanalista; Mestre em Teoria Psicanalítica pela Universidade Federal do Rio de Janeiro - UFRJ (Rio de Janeiro, RJ, Br), com Especializações em Clínica Psicanalítica e Saúde Mental pelo Instituto de Psiquiatria - IPUB/UFRJ. Participante da Escola Brasileira de Psicanálise, EBP-Rio.

Rua Capistrano de Abreu, 14 - Botafogo

22271-000 Rio de Janeiro, RJ, Br

\section{Ana Paola Frare}

Psicóloga e Psicanalista; Doutora em pesquisa e clínica psicanalítica; Professora Adjunta da Universidade Federal Fluminense - UFF (Niterói, RJ, Br).

Universidade Federal Fluminense, E.C.H.S.V.R.

Rua Desembargador Ellis Ermydio Figueira, 783, Bloco A, sl. 311 - Aterrado

27213-145 Volta Redonda, RJ, Br

This is an open-access article, which permits unrestricted use, distribution, (cc) BY-NC and reproduction in any medium for non-commercial purposes provided the original authors and sources are credited. 